\title{
Effect of Spaceflight on Tomato Seed Quality and Biochemical Characteristics of Mature Plants
}

\author{
Elena Dzhos ${ }^{1}$, Nadezhda Golubkina ${ }^{1, *}$, Marina Antoshkina ${ }^{1}$, Irina Kondratyeva ${ }^{1}$, Andrew Koshevarov ${ }^{1}$, \\ Anton Shkaplerov ${ }^{2}$, Tatiana Zavarykina ${ }^{3,4}$, Galina Nechitailo ${ }^{3}$ and Gianluca Caruso 5 \\ 1 Federal Scientific Center of Vegetable Production, Selectsionnaya 14, 143072 Moscow, Russia; \\ elenadzhos@mail.ru (E.D.); limont_m@mail.ru (M.A.); tomatvniissok@mail.ru (I.K.); zato@inbox.ru (A.K.) \\ 2 Yuri Gagarin Cosmonaut Training Center, Star City, 141160 Moscow, Russia; shkaplerov@mail.ru \\ 3 Emanuel Institute of Biochemical Physics RAS, Kosigina 4, 119334 Moscow, Russia; \\ tpalievskaya@yandex.ru (T.Z.); spacemal@mail.ru (G.N.) \\ 4 Federal Scientific Center "Nemchinovka", Agrokhimikov 6, Novoivanovskoe, 143026 Moscow, Russia \\ 5 Department of Agricultural Sciences, University of Naples Federico II, Portici, 80055 Naples, Italy; \\ gcaruso@unina.it \\ * Correspondence: segolubkina45@gmail.com
}

check for

updates

Citation: Dzhos, E.; Golubkina, N.; Antoshkina, M.; Kondratyeva, I.; Koshevarov, A.; Shkaplerov, A.;

Zavarykina, T.; Nechitailo, G.; Caruso, G. Effect of Spaceflight on Tomato Seed Quality and Biochemical Characteristics of Mature Plants. Horticulturae 2021, 7, 89. https:// doi.org/10.3390/horticulturae7050089

Academic Editor: Leo Sabatino

Received: 1 April 2021

Accepted: 20 April 2021

Published: 22 April 2021

Publisher's Note: MDPI stays neutral with regard to jurisdictional claims in published maps and institutional affiliations.

Copyright: (c) 2021 by the authors. Licensee MDPI, Basel, Switzerland. This article is an open access article distributed under the terms and conditions of the Creative Commons Attribution (CC BY) license (https:/ / creativecommons.org/licenses/by/ $4.0 /)$.

\begin{abstract}
Intensive space exploration includes profound investigations on the effect of weightlessness and cosmic radiation on plant growth and development. Tomato seeds are often used in such experiments though up to date the results have given rather vague information about biochemical changes in mature plants grown from seeds subjected to spaceflight. The effect of half a year of storage in the International Space Station (ISS) on tomato seeds (cultivar Podmoskovny ranny) was studied by analyzing the biochemical characteristics and mineral content of mature plants grown from these seeds both in greenhouse and field conditions. A significant increase was recorded in ascorbic acid, polyphenol and carotenoid contents, and total antioxidant activity (AOA), with higher changes in the field conditions compared to greenhouse. Contrary to control plants, the ones derived from space-stored seeds demonstrated a significant decrease in root AOA. The latter plants also showed a higher yield, but lower content of fruit dry matter, sugars, total dissolved solids and organic acids. The fruits of plants derived from space-stored seeds demonstrated decreased levels of Fe, $\mathrm{Cu}$ and taste index. The described results reflect the existence of oxidative stress in mature tomato plants as a long-term consequence of the effect of spaceflight on seed quality, whereas the higher yield may be attributed to genetic modifications.
\end{abstract}

Keywords: space-stored seeds; Solanum lycopersicum L.; weightlessness; cosmic radiation; antioxidants

\section{Introduction}

International space stations provide unique conditions for the investigation of the effects of space radiation and microgravity on plant growth and development [1-5]. Such experiments can serve as the basis for subsequent cultivation of vegetable crops in space during long-distance spaceflights, for understanding the mechanisms of physiological changes in plants and for evaluating the prospects of quick plant selection from space seeds [1,6-8].

Previous investigations of the effects of space radiation and microgravity on plant growth and development achieved on Russian and American space stations revealed insignificant changes in plant morphology, which suggests good prospects of plant cultivation in space $[9,10]$. Another direction of investigations includes studies of the effect of space on the quality of both the seeds and the plants grown from these seeds on the Earth. According to Liu et al. [11], this direction opens high prospects of quick plant selection aimed to increase yield, tolerance to diseases and vegetation period shortening. A series of such investigations were completed on different agricultural crops, and a beneficial 
effect of spaceflight was demonstrated on rice seeds [11]. On the other hand, the results obtained in recent times are often controversial. Indeed, investigations on rocket seeds [12] showed that spaceflight reduced seed germination vigor and increased aging sensitivity but did not compromise seed viability and the development of normal seedlings. An investigation on tomato seeds after 6 years of spaceflight indicated that the tested plants exhibited higher variability in yield than the control ones, and some of the tested plants were infertile; moreover, various differences in cell walls, chloroplasts and mitochondria were observed. The results obtained point out significant changes occurring at the molecular level in tomato plants [10,13]. Experiments carried out in Ukraine [14] demonstrated that spaceflight conditions during a 6-year exposure of tomato seeds increased tomato productivity, whereas the plants were more resistant to viruses and had higher polyphenol concentration than those of the stationary control. In the early experiment of Kahn and Stoffella [15], the authors showed that tomato seeds could survive in space for several years without adverse effects on germination, emergence and fruit yield. Investigations of the effect of 15-day spaceflight revealed acceleration of alfalfa seed germination and inhibition of the root growth due to chromosomal damage and abnormal mitosis induced by cosmic radiation [16]. Other results revealed reduced germination, lethality, sterility and accelerated senescence [17-19].

The chronic exposure to low doses of ionizing radiation also led to significant differences in the expression of radical scavenging enzymes and DNA-repair genes and an increase in the activity of several antioxidant enzymes [20].

Long-term exposure to microgravity inside spaceships also resulted in the important discovery that these conditions are associated with accelerated aging of humans and plants $[4,21]$. The conditions of space stations reduced seed vigor and viability, which are connected with oxidation of the most important molecules: proteins, lipids and nucleic acids $[22,23]$. The best shielding for crop seed transport during long-distance space travel was the seed storage inside spaceships [12].

The aim of the present study was to conduct a quality evaluation of mature tomato plants grown from seeds exposed to half a year of spaceflight on the International Space Station (ISS).

\section{Materials and Methods}

Tomato seeds (Solanum lycopersicum L., cultivar Podmoskovny ranny of dwarf type) were obtained in 1992 and exposed in the cosmic station Mir (from 1992 to 1998). After returning to the Earth, 8 generations of plants were grown both in greenhouse and open field [13], and only the seeds of the 8th tomato generation were used in the present research. Seeds were transported to the International Space Station (ISS) on 19 December 2017 by the cosmonaut Shraplerov through the transportable manned spacecraft MS-07. Space-treated seeds were stored for six months inside the ISS, at the average temperature of $22-23^{\circ} \mathrm{C}$. The seed samples were brought back to the Earth on 3 June 2018. Control seeds of cultivar Podmoskovny ranny had been kept at room temperature in the laboratory of the Emanuel Institute of Biochemical Physics since 1998.

\subsection{Growing Conditions and Experimental Protocol}

Seeds of tomato (cultivar Podmoskovny ranny) kept for half a year in the ISS and seeds of control plants were used in the present investigation.

A research was carried out in 2020 on plants grown in (a) unheated film-covered greenhouse and (b) in open field, at the experimental fields of Federal Scientific Center of Vegetable Production (Moscow region, $55^{\circ} 39.51^{\prime} \mathrm{N}, 37^{\circ} 12.23^{\prime} \mathrm{E}$ ), on sod-podzolic clay-loam soil, $\mathrm{pH} 6.8,2.1 \%$ organic matter, $1.1 \mathrm{~g} \cdot \mathrm{kg}^{-1} \mathrm{~N}, 0.045 \mathrm{~g} \cdot \mathrm{kg}^{-1} \mathrm{P}_{2} \mathrm{O}_{5}, 0.357 \mathrm{~g} \cdot \mathrm{kg}^{-1} \mathrm{~K}_{2} \mathrm{O}$. The mean values of temperature $\left({ }^{\circ} \mathrm{C}\right)$ and relative humidity $(\%)$ were the following: 16.1 and 71.8 in May, 21.0 and 73.0 in June, 23.8 and 74.9 in July, 19.0 and 76.9 in August and 14.8 and 86.0 in September. 
Upon the 22 April sowing, the control seeds showed 33\% germination and spacetreated seeds reached $61 \%$. The seedlings were transferred into cassettes $(5 \times 5 \mathrm{cv})$ with a peat mix substrate containing mineral fertilizers and $\mathrm{pH}$ 6.5-7. Most of the seedlings emerged on 4 May and were transplanted in greenhouse on 28 May and in open field on 16 June, when they had 6-7 true leaves, with 3 plants per $\mathrm{m}^{2}$, and each treatment was replicated thrice. Fertilization was practiced by supplying $30 \mathrm{~kg} \cdot \mathrm{ha}^{-1} \mathrm{~N}$ (ammonium sulfate), $60 \mathrm{~kg} \cdot \mathrm{ha}^{-1} \mathrm{P}_{2} \mathrm{O}_{5}$ (superphosphate) and $100 \mathrm{~kg} \cdot \mathrm{ha}^{-1}$ (potassium sulfate) prior to planting and $50 \mathrm{~kg} \cdot \mathrm{ha}^{-1} \mathrm{~N}$ (ammonium nitrate) during the crop cycle in two applications, two and five weeks after transplant, respectively.

At harvest, started in early August, the following determinations were performed in all plots: plant height; weight of tomato fruits; number of marketable trusses per plant.

\subsection{Resistance to Phytophtorosis}

The evaluation of plant resistance to phytophtorosis was carried out during the natural development of the disease against a severe infection background, according to the guidelines for tomato selection relevant to phytophtorosis resistance [24].

\subsection{Sample Preparation}

Ten samples of healthy red-ripe stage fruit were used, harvested in August. Each sample consisted of at least three tomatoes from the second to fourth trusses, with a minimum total weight for sample of $250 \mathrm{~g}$.

After harvesting, leaves, fruits and roots were separated and weighed; roots were washed with water and dried with filter paper. Samples were homogenized, and fresh homogenates were used for the determination of ascorbic acid, nitrates and total dissolved solids (TDS). Some of the samples were dried at $70{ }^{\circ} \mathrm{C}$ to constant weight and used for the determination of total polyphenol content (TP), total antioxidant activity (AOA) and mineral composition.

\subsection{Dry Matter}

The dry matter was assessed gravimetrically by drying the samples in an oven at $70{ }^{\circ} \mathrm{C}$ until constant weight.

\subsection{Ascorbic Acid}

The ascorbic acid content was determined by visual titration of plant extracts in $6 \%$ trichloracetic acid with Tillman's reagent [25]. Three grams of fresh tomato fruits were homogenized in a porcelain mortar with $5 \mathrm{~mL}$ of $6 \%$ trichloracetic acid and quantitatively transferred to a measuring cylinder. The volume was brought to $60 \mathrm{~mL}$ using trichloracetic acid, and the mixture was filtered through filter paper 15 min later. The concentration of ascorbic acid was determined from the amount of Tillman's reagent that went into titration of the sample.

\subsection{Preparation of Ethanolic Extracts}

Half a gram of dry homogenized tomato fruit or root powder was extracted with $20 \mathrm{~mL}$ of $70 \%$ ethanol at $80{ }^{\circ} \mathrm{C}$ over $1 \mathrm{~h}$. The mixture was cooled and quantitatively transferred to a volumetric flask, and the volume was adjusted to $25 \mathrm{~mL}$. The mixture was filtered through filter paper and used further for the determination of polyphenols and total antioxidant activity.

\subsection{Total Polyphenols (TP)}

Polyphenols were determined spectrophotometrically based on the Folin-Ciocalteu colorimetric method according to Golubkina et al. [26]. The concentration of polyphenols was calculated according to the absorption of the reaction mixture at $730 \mathrm{~nm}$ using $0.02 \%$ gallic acid as an external standard. The results were expressed in mg of gallic acid equivalent per $\mathrm{g}$ of dry weight (mg GAE $\mathrm{g}^{-1}$ d.w.). 


\subsection{Antioxidant Activity ( $A O A)$}

The antioxidant activity was evaluated via titration of $0.01 \mathrm{~N} \mathrm{KMnO}_{4}$ solution with ethanolic extracts of dry samples [26].

\subsection{Total Dissolved Solids (TDS)}

TDS were determined in water extracts using TDS-3 conductometer (HM Digital, Inc., Seoul, Korea) and expressed in $\mathrm{mg} \mathrm{kg}^{-1}$ d.w.

\subsection{Nitrates}

Nitrates were assessed using ion-selective electrode on ionomer Expert-001 (Econix Inc., Moscow, Russia).

\subsection{Monosaccharides (SS)}

The monosaccharides were determined using the ferricyanide colorimetric method based on the reaction of monosaccharides with potassium ferricyanide [27]. The total sugars were analogically determined after acidic hydrolysis of water extracts with $20 \%$ hydrochloric acid. Fructose was used as an external standard.

\subsection{Titratable Acidity (TA)}

TA was determined potentiometrically by titrating a $50 \mathrm{~mL}$ diluted (1:5) sample with $0.1 \mathrm{~N} \mathrm{NaOH}$ to $\mathrm{pH} 8.1$ on ionomer Expert 001 (Econix Inc., Russia) and was expressed as percentage of citric acid.

\subsection{Taste Index (TI)}

TI was determined according to Navez et al. [28] from the total sugar content (TS) and TA values using the formula

$$
\mathrm{TI}=\mathrm{TA}+\mathrm{TS} /(20 \times \mathrm{TA}) .
$$

\subsection{Carotenoid Content}

Determination of carotenoid content was achieved according to Golubkina et al. [26]. First, $0.5 \mathrm{~g}$ of homogenized sample was ground in a mortar with ceramic powder and extracted with small portions of acetone until color disappearance. The combined extract was diluted with $9 \mathrm{~mL}$ of hexane and washed 4-5 times with distilled water to remove traces of acetone. The residual extract was quantitatively transferred to a volumetric flask, and the volume was adjusted to $10 \mathrm{~mL}$. The resulting extract was mixed, filtered through a small portion of anhydrous $\mathrm{Na}_{2} \mathrm{SO}_{4}$ and subjected to the analysis. The separation of carotenoids was achieved using quantitative thin-layer chromatography on Whatman 3A chromatographic paper in two chromatographic systems: (1) hexane to separate $\beta$-carotene and (2) hexane-acetone, 10:0.5, for separation of lycopene and lutein. Appropriate zones of carotenoid compounds were cut out and filled with $3 \mathrm{~mL}$ of hexane. The determination of carotenoid content in tomato fruit was performed using appropriate specific absorption $\mathrm{E}^{1 \%}{ }_{1 \mathrm{~cm}}$ for $\beta$-carotene $(2580$ at $\lambda=450 \mathrm{~nm})$, lycopene (3470 at $\lambda=474 \mathrm{~nm}$ ) and lutein (2560; $\lambda=447 \mathrm{~nm}$ ). The internal standards were $\beta$-carotene, lutein and lycopene from Sigma Inc. (Kawasaki, Japan).

\subsection{Statistical Analysis}

Data were processed by analysis of variance, and mean separations were performed through the Duncan multiple range test, with reference to 0.05 probability level, using SPSS software version 21 (IBM, Armonk, NY, USA). Data expressed as percentages were subjected to angular transformation before processing. 


\section{Results and Discussion}

Tomato plants grown both from control and space-stored seeds had a shorter crop cycle in greenhouse (90-94 days) compared to open field (115-120 days) (Table 1), due to the higher temperatures recorded in the first environment. The differences in crop cycle length between plants from space-stored and control seeds were 5 and 4 days in open field and greenhouse respectively.

Table 1. Phenological progress of tomato plants grown in greenhouse and in open field, from control and spaceflight-exposed seeds, expressed as days from sowing referring to $50 \%$ of plants that reached each stage.

\begin{tabular}{ccccc}
\hline & \multicolumn{2}{c}{ Control Seeds } & \multicolumn{2}{c}{ Space-Stored Seeds } \\
\cline { 2 - 5 } & Greenhouse & Field & Greenhouse & Field \\
\hline Two-leaf stage & 13 & 13 & 12 & 12 \\
Flowering & 52 & 57 & 49 & 56 \\
Fruit ripening & 94 & 115 & 90 & 120 \\
\hline
\end{tabular}

\subsection{Yield, Dry Matter Content, TDS and Nitrates}

Higher height, fruit yield and marketability were recorded for tomato plants grown from space-stored seeds compared to the control ones, with higher values in the more favorable growth conditions in greenhouse (Table 2). The plants derived from space-stored seeds also showed better tolerance to diseases in the field conditions compared to control plants, which was in accordance with the results of the previous investigation [14].

Table 2. Plant height, fruit yield, dry weight and disease occurrence of tomato grown in greenhouse and in open field, from control and spaceflight-exposed seeds.

\begin{tabular}{ccccc}
\hline & \multicolumn{2}{c}{ Control Seeds } & \multicolumn{2}{c}{ Space-Stored Seeds } \\
\cline { 2 - 5 } & Greenhouse & Field & Greenhouse & Field \\
\hline Plant height $(\mathrm{cm})$ & $65 \mathrm{~b}$ & $57 \mathrm{c}$ & $77 \mathrm{a}$ & $78 \mathrm{a}$ \\
Yield $\left(\mathrm{t} \mathrm{ha}^{-1}\right)$ & $39.0 \mathrm{~b}$ & $34.3 \mathrm{c}$ & $42.0 \mathrm{a}$ & $36.9 \mathrm{~b}$ \\
Fruit weight $(\mathrm{g})$ & $58 \mathrm{~b}$ & $52 \mathrm{c}$ & $63 \mathrm{a}$ & $56 \mathrm{~b}$ \\
Number of trusses per plant & $5 \mathrm{a}$ & $4 \mathrm{~b}$ & $5 \mathrm{a}$ & $87 \mathrm{bc}$ \\
Marketability (\%) & $89 \mathrm{ab}$ & $85 \mathrm{c}$ & $3.0 \mathrm{a}$ \\
Diseases (number of points) & $3.0 \mathrm{a}$ & $2.5 \mathrm{~b}$ & $3.0 \mathrm{a}$ & $6.4 \pm 0.5 \mathrm{c}$ \\
Dry matter (\%) & $11.5 \pm 1.0 \mathrm{a}$ & $7.1 \pm 0.6 \mathrm{bc}$ & $8.2 \pm 0.6 \mathrm{~b}$ & \\
\hline
\end{tabular}

In each row, the values with the same letters do not differ statistically according to Duncan test at $p<0.05$.

At the same time, a significant decrease in fruit dry matter content was found in the fruits obtained from plants derived from space-stored seeds compared to control ones. Notably, in greenhouse conditions, the fruit dry matter associated with the seed space treatment was 1.4 times lower than that of control plant fruits, while the corresponding difference in the open-field-grown plants was only 1.12-fold.

At the same time, the total dissolved solids (TDS) did not differ statistically between fruits produced from control and those obtained from space-treated seeds, though the latter merely showed a slight decreasing tendency. TDS values detected by portable conductometer reflect both the amount of soluble solids and the organic acid content. As can be seen in Figure 1, higher TDS values were recorded in greenhouse conditions, which is connected with a higher nutrient uptake rate.

A similar phenomenon was observed for nitrate accumulation, though with greater differences between the control fruits and those produced by the plants derived from space-stored seeds (Figure 2). The latter results are not surprising, taking into account that all nitrate derivatives are highly soluble in water. 


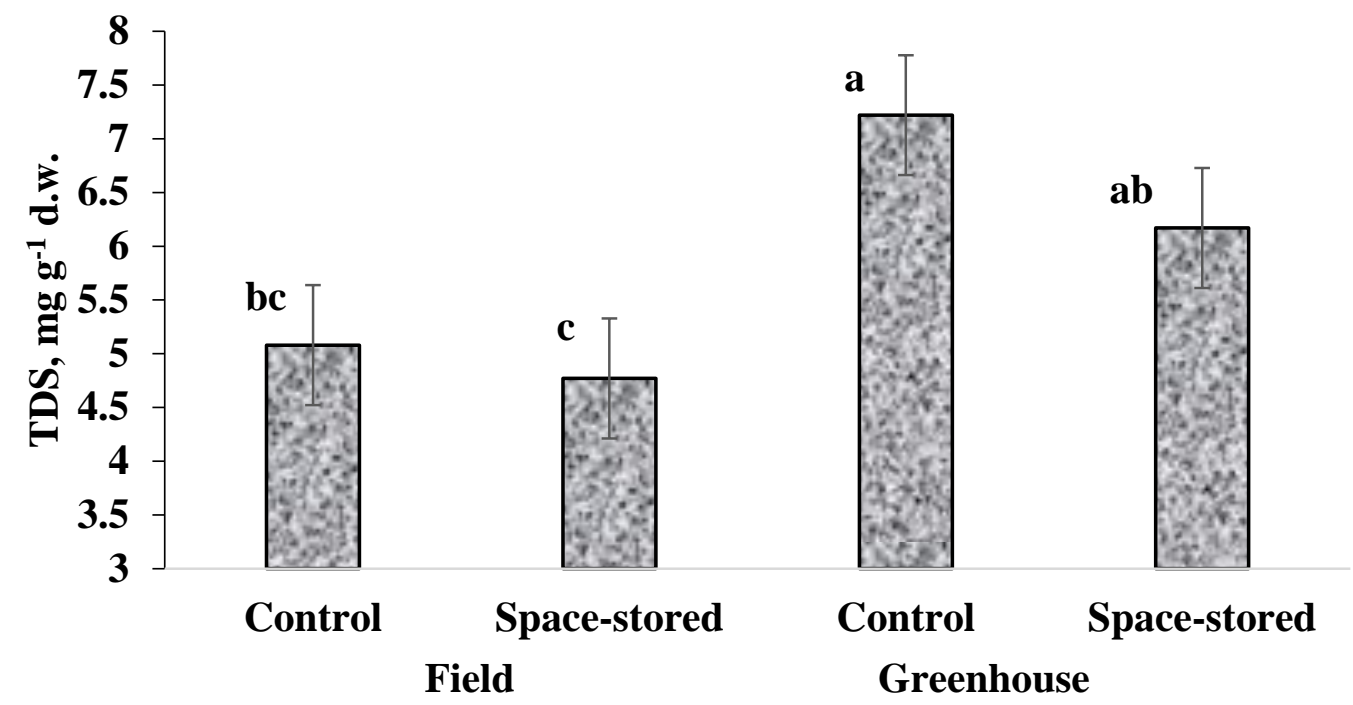

Figure 1. TDS content in tomato fruits grown from control and spaceflight-exposed seeds, in open field and in greenhouse. Values with the same letters do not differ statistically according to Duncan test at $p<0.05$.

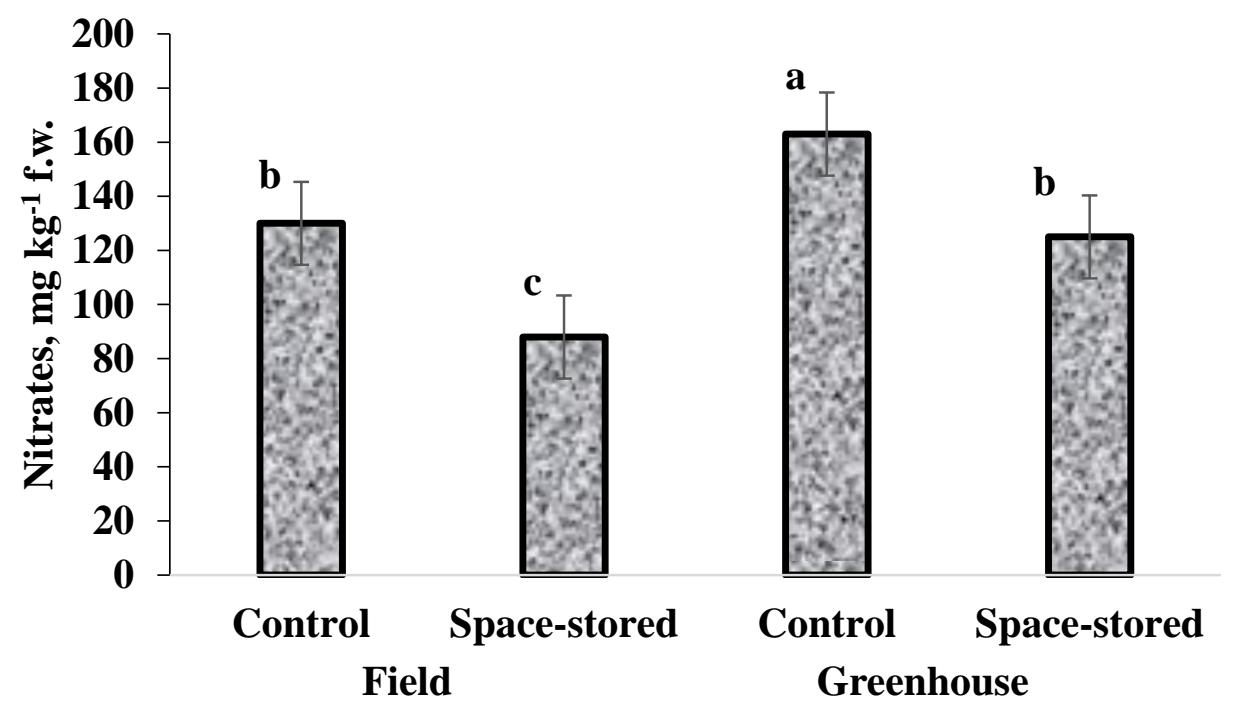

Figure 2. Nitrate accumulation in tomato fruits grown from control and spaceflight-exposed seeds, in open field and in greenhouse. Values with the same letters do not differ statistically according to Duncan test at $p<0.05$.

\subsection{Antioxidant Status}

Secondary metabolites and antioxidants in particular are known to be involved in the process of stress adaptation [29]. Tomato fruits are rich in antioxidants, including carotenoids, polyphenols and ascorbic acid, demonstrating high biological activity, thus reducing the risk of cancer and cardiovascular diseases [30,31]; improving immunity [32]; and showing neuroprotective, anti-inflammatory and antimicrobial properties [33]. The most common carotenoids of tomato fruits are $\beta$-carotene, lutein and lycopene, which are synthesized at the highest levels in red varieties [34]. The data shown in Figure 3 indicate that the $\beta$-carotene/lycopene/lutein ratio in ordinary growing conditions of cultivar Podmoskovny reached 1.00:5.02:1.01 in open field and 1.00:7.50:1.03 in greenhouse, with a significantly higher total carotenoid content in the former case $\left(152.7 \mathrm{mg} 100 \mathrm{~g}^{-1}\right.$ d.w. vs. $127.4 \mathrm{mg} 100 \mathrm{~g}^{-1} \mathrm{~d}$.w. with $p<0.01$ significance). The corresponding carotenoid ratio in fruits of plants derived from space-stored seeds was equal to 1.00:3.90:1.04 in open field conditions and 1.00:7.10:0.94 in greenhouse. Taking into account that lycopene is a precursor in the biosynthesis of $\beta$-carotene and lutein, it may be inferred either that the 
reduction of lycopene biosynthesis took place in greenhouse or that the transformation of lycopene to $\beta$-carotene and lutein in these conditions was reduced both in control plants and in plants derived from space-stored seeds. Furthermore, the significant increase in total carotenoid content due to the spaceflight effect on tomato seed quality proves the existence of oxidative stress in plants derived from space-stored seeds, which is reflected by the increase in the total carotenoid content by $15 \%$ in tomato fruits produced in open field and by $28 \%$ in greenhouse (Figure 3 ).

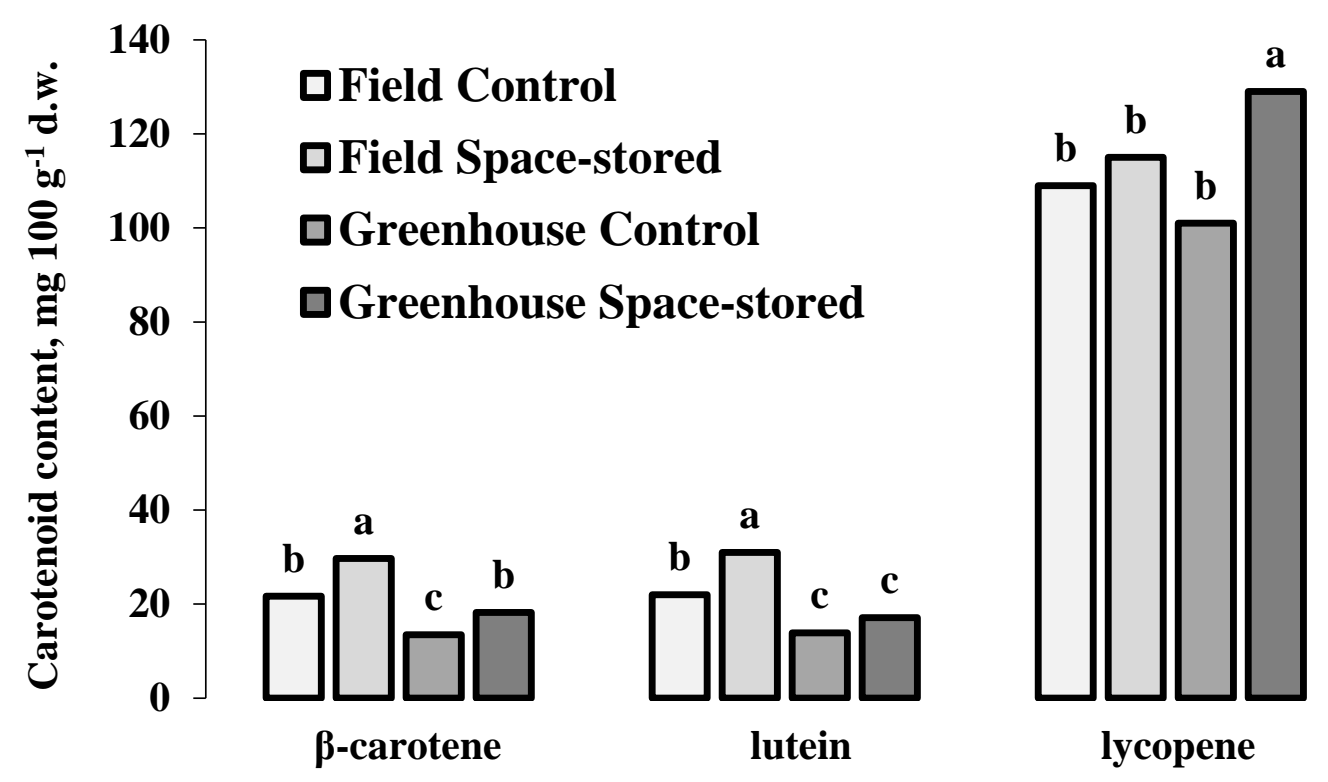

Figure 3. Carotenoid profile of tomato fruits obtained from control plants and plants derived from space-stored seeds grown in open field and in greenhouse. For each carotenoid, values with the same letters do not differ statistically according to Duncan test at $p<0.05$.

Ascorbic acid (AA) plays an important role in plant antioxidant defense, being a key substrate for the detoxification of reactive oxygen species [35]. Overproduction of reactive oxygen species (ROS) in plants under stress conditions is reduced by the production of enzymatic and nonenzymatic antioxidants. In this respect, AA is one of the universal nonenzymatic antioxidants having substantial potential for scavenging ROS and also modulating a number of fundamental functions in plants both under stress and unstressed conditions. The data of ascorbic acid content in control tomato fruits and tomato fruits derived from space-stored seeds (Table 3) are given on a dry weight basis in order to make an adequate comparison between the treatments having different levels of dry matter. In this respect, the results indicate rather small differences in tomato fruit AA content between control plants and plants derived from space-stored seeds, which reached $6.3 \%$ in open field and $20 \%$ in greenhouse. In the latter conditions, a similar increase in total antioxidant activity was recorded (21.1\%), whereas no AOA differences arose in open field.

Phenolics in tomato fruits, represented by chlorogenic acid and quercetin [34], are important antioxidants both for plant integrity and human health [33] and the major contributors to antioxidant activity in tomatoes [36]. In the present investigation, total phenolics are of special interest as the differences in their content between control plants and plants derived from space-stored seeds reached the highest values of $26.7 \%$ in greenhouse and $36.3 \%$ in open field. Contrary, no differences in phenolic levels were observed between tomato fruits grown in greenhouse and open field. Interestingly, among the antioxidants studied, polyphenols proved to be the most sensitive to long-term consequences of spaceflight. 
Table 3. Antioxidant compounds and activity of tomato fruits obtained from control and spaceflight-exposed seeds, in greenhouse and in open field.

\begin{tabular}{|c|c|c|c|c|}
\hline \multirow{2}{*}{ Parameter } & \multicolumn{2}{|c|}{ Control Seeds } & \multicolumn{2}{|c|}{ Space-Stored Seeds } \\
\hline & Greenhouse & Field & Greenhouse & Field \\
\hline \multicolumn{5}{|c|}{ Fruits } \\
\hline AA (mg $100 \mathrm{~g}^{-1}$ d.w.) & $399 \pm 30 c$ & $537 \pm 40 \mathrm{ab}$ & $479 \pm 35 b$ & $571 \pm 42 \mathrm{a}$ \\
\hline AOA (mg GAE g ${ }^{-1}$ d.w.) & $18.0 \pm 1 \mathrm{~b}$ & $22.5 \pm 1 \mathrm{a}$ & $21.8 \pm 1 \mathrm{a}$ & $22.5 \pm 1 \mathrm{a}$ \\
\hline TP (mg GAE g ${ }^{-1}$ d.w.) & $13.4 \pm 1 \mathrm{~b}$ & $13.5 \pm 0.9 b$ & $17.1 \pm 1 \mathrm{a}$ & $18.4 \pm 1 \mathrm{a}$ \\
\hline \multicolumn{5}{|c|}{ Roots } \\
\hline AOA (mg GAE g ${ }^{-1}$ d.w.) & $10.7 \pm 0.8 \mathrm{a}$ & $12.6 \pm 1.0 \mathrm{a}$ & $6.5 \pm 0.3 b$ & $8.7 \pm 0.4 c$ \\
\hline TP (mg GAE g ${ }^{-1}$ d.w.) & $7.0 \pm 0.5 \mathrm{a}$ & $6.8 \pm 0.4 \mathrm{a}$ & $6.5 \pm 0.3 \mathrm{ab}$ & $6.0 \pm 0.3 b$ \\
\hline
\end{tabular}

AA: ascorbic acid; AOA: antioxidant activity; TP: total phenolics. In each row, the values with the same letters do not differ statistically according to Duncan test at $p<0.05$.

The comparison between the antioxidant status of tomato fruits and roots revealed the opposite tendency in antioxidant distribution, especially pronounced in AOA values. Indeed, while root TP decreased in plants derived from space-stored seeds, reaching only $13.3 \%$ in open field and $7.7 \%$ in greenhouse, root AOA values decreased by $44.8 \%$ and $64.6 \%$, respectively (Table 3 ). The latter phenomenon indirectly indicates the possibility of antioxidant redistribution in plants derived from space-stored seeds, with the AOA showing a decrease in roots and increase in fruits.

\subsection{Monosaccharides, Organic Acids, Taste}

Organic acids together with sugars are the main soluble components of ripe fruits and have a major effect on taste, being responsible for sourness and contributing to the flavor; it is well known that sugar and organic acid contents are positively correlated in tomato fruit [37]. Contrary to soluble carbohydrates, which are translocated into the fruits as products of photosynthesis, organic acids are synthesized predominantly in fruits from imported sugars. Fruit acidity, measured by titratable acidity and/or $\mathrm{pH}$, is an important component of fruit organoleptic quality [38], and it is connected to the presence of organic acids, with malic and citric acids being the main acids found in most ripe fruits [39]. Both genetic and environmental variations affect organic acid accumulation in tomato fruits. Notably, nitrate accumulation may stimulate organic acid biosynthesis [40], and in this respect, decreased levels of nitrates and TDS result in decreased TA values.

Though recent investigations indicated a significant role of total antioxidant activity (AOA), total phenolics (TP) and ascorbic acid (AA) content in tomato fruit taste [40,41], only one equation between sugar and organic acids content is presently used for appropriate evaluation [28,34,42]. Monosaccharides (glucose and fructose, present at equimolar ratios) are known to dominate in tomato fruits with a negligible amount of disaccharides [43]. Differences in titratable acidity (TA) between control fruits and fruits derived from spacestored seeds were as much as $35.1 \%$ in open field and $50 \%$ in greenhouse conditions. Citric acid is known to prevail in tomato fruit organic acids [33], whereas malic and oxalic acids contribute to a lesser extent to the titratable acidity value [44]. As can be inferred from the above data, both TDS and TA demonstrated similar differences between control plants and plants derived from space-stored seeds; i.e., they were higher in greenhouse fruits than in the open field ones. Furthermore, according to taste maturity index (TM = TS:TA) [28], fruit of control plants and plants developed from space-stored seeds did not differ at the stage of maturity, with the TM index being equal to 9.00-9.47 for greenhouse plants and 7.56-7.60 for those grown in open field. In this respect, the taste index of fruit from control plants and plants derived from space-stored seeds, calculated according to Navez et al. [28], revealed higher values in greenhouse and lower in open field (Table 4). 
Table 4. Monosaccharide and organic acid contents, and taste index (TI) of tomato fruits obtained from control and spaceflight-exposed seeds, in greenhouse and in open field.

\begin{tabular}{ccccc}
\hline \multirow{2}{*}{ Parameter } & \multicolumn{2}{c}{ Control Seeds } & \multicolumn{2}{c}{ Space-Stored Seeds } \\
\cline { 2 - 5 } & Greenhouse & Field & Greenhouse & Field \\
\hline Brix (\% f.w.) & $7.1 \pm 0.4 \mathrm{a}$ & $3.8 \pm 0.2 \mathrm{~b}$ & $4.2 \pm 0.2 \mathrm{~b}$ & $2.8 \pm 0.1 \mathrm{c}$ \\
TS (\% f.w.) & $7.1 \pm 0.3 \mathrm{a}$ & $3.8 \pm 0.2 \mathrm{c}$ & $4.5 \pm 0.3 \mathrm{~b}$ & $2.8 \pm 0.2 \mathrm{~d}$ \\
TA (\% f.w.) & $0.75 \pm 0.04 \mathrm{a}$ & $0.50 \pm 0.03 \mathrm{~b}$ & $0.50 \pm 0.03 \mathrm{~b}$ & $0.37 \pm 0.02 \mathrm{c}$ \\
TI & 1.22 & 0.88 & 0.92 & 0.78 \\
TM & 9.47 & 7.60 & 9.00 & 7.57 \\
\hline
\end{tabular}

TS: total sugar; TA: titratable acidity; TI: taste index; TM: taste maturity index. In each row, the values with the same letters do not differ statistically according to Duncan test at $p<0.05$.

The recorded monosaccharide trends were similar to TDS changes (Figure 1), as monosaccharides are one of the main components of water-soluble extracts in tomato fruits. Notably, the results indicate a significant decrease in fruit sugar content of plants derived from space-stored seeds, as much as $35.7 \%$ and $57.8 \%$ in open field and greenhouse, respectively (Table 4), which is in contradiction with the hypothesis of oxidant stress development. According to literature reports [45], carbohydrates also participate in plant antioxidant defense, and their amount usually increases as a consequence of stress conditions. The opposite differences recorded in the present research for fruits of plants derived from space-stored seeds were statistically significant for values calculated on a dry weight basis, i.e., $12.4 \%$ decrease for fruits grown in greenhouse and $22.1 \%$ decrease for fruits grown in open field.

\subsection{Elemental Composition}

Changes in fruit elemental composition were revealed only for $\mathrm{Fe}$ and $\mathrm{Cu}$ content, whose concentrations in fruits derived by space-stored seeds decreased by 1.5 and 1.24 times compared to control plants in greenhouse conditions and by 1.4 and 1.3 times in open field (Table 5). No differences were detected for Mn and $\mathrm{Zn}$ content in fruit between control plants and plants derived from space-stored seeds.

Table 5. Elemental composition of tomato fruits obtained from control and spaceflight-exposed seeds, in greenhouse and in open field ( $\mathrm{mg} \mathrm{kg}^{-1}$ d.w.).

\begin{tabular}{cccccc}
\hline Growing Environment & Seed Origin & Zn & Mn & Fe & Cu \\
\hline \multirow{2}{*}{ Greenhouse } & control & $7.0 \pm 0.5 \mathrm{ab}$ & $5.5 \pm 0.4 \mathrm{bc}$ & $45.8 \pm 3.7 \mathrm{a}$ & $3.1 \pm 0.2 \mathrm{a}$ \\
& space-stored & $6.2 \pm 0.4 \mathrm{~b}$ & $4.8 \pm 0.3 \mathrm{c}$ & $29.8 \pm 2.0 \mathrm{~b}$ & $2.5 \pm 0.1 \mathrm{~b}$ \\
\hline \multirow{2}{*}{ Open field } & control & $8.7 \pm 0.7 \mathrm{a}$ & $6.8 \pm 0.5 \mathrm{a}$ & $39.8 \pm 3.1 \mathrm{a}$ & $3.0 \pm 0.2 \mathrm{a}$ \\
& space-stored & $7.8 \pm 0.7 \mathrm{a}$ & $6.0 \pm 0.5 \mathrm{ab}$ & $28.4 \pm 0.2 \mathrm{~b}$ & $2.3 \pm 0.1 \mathrm{~b}$ \\
\hline
\end{tabular}

Within each column, the values with the same letters do not differ statistically according to Duncan test at $p<0.05$.

Iron is an essential micronutrient for almost all living organisms, playing a critical role in DNA synthesis, photosynthesis and respiration [46]. In plants, iron is involved in chlorophyll synthesis, and it is essential for maintaining chloroplast structure and function [47]. As far as $\mathrm{Cu}$ is concerned, this microelement is known to serve as an essential cofactor in plant proteins, performing pivotal functions in plant cells by participating in electron transport [48]. Based on the above reports, reduced levels of $\mathrm{Cu}$ and Fe may be connected to decreased levels of monosaccharides in tomatoes from space-stored seeds [48].

\subsection{Relationships between the Analyzed Parameters}

From the results of biochemical and mineral analyses, important characteristics of plants grown from space-kept seeds were revealed (Figure 4). The high levels of antioxidant parameters and the decrease in $\mathrm{Fe}$ and $\mathrm{Cu}$ accumulation are in agreement with the existence of significant oxidative stress. The decrease in sugar, dry matter and organic acid contents 
is in accordance with lower taste index values in fruits derived from space-stored seeds. The controversial aspect lies in the fact that despite the reduced accumulation of Fe, $\mathrm{Cu}$, dry matter and carbohydrates, the plants grown from space-kept seeds demonstrated higher yield, fruit weight and plant height.

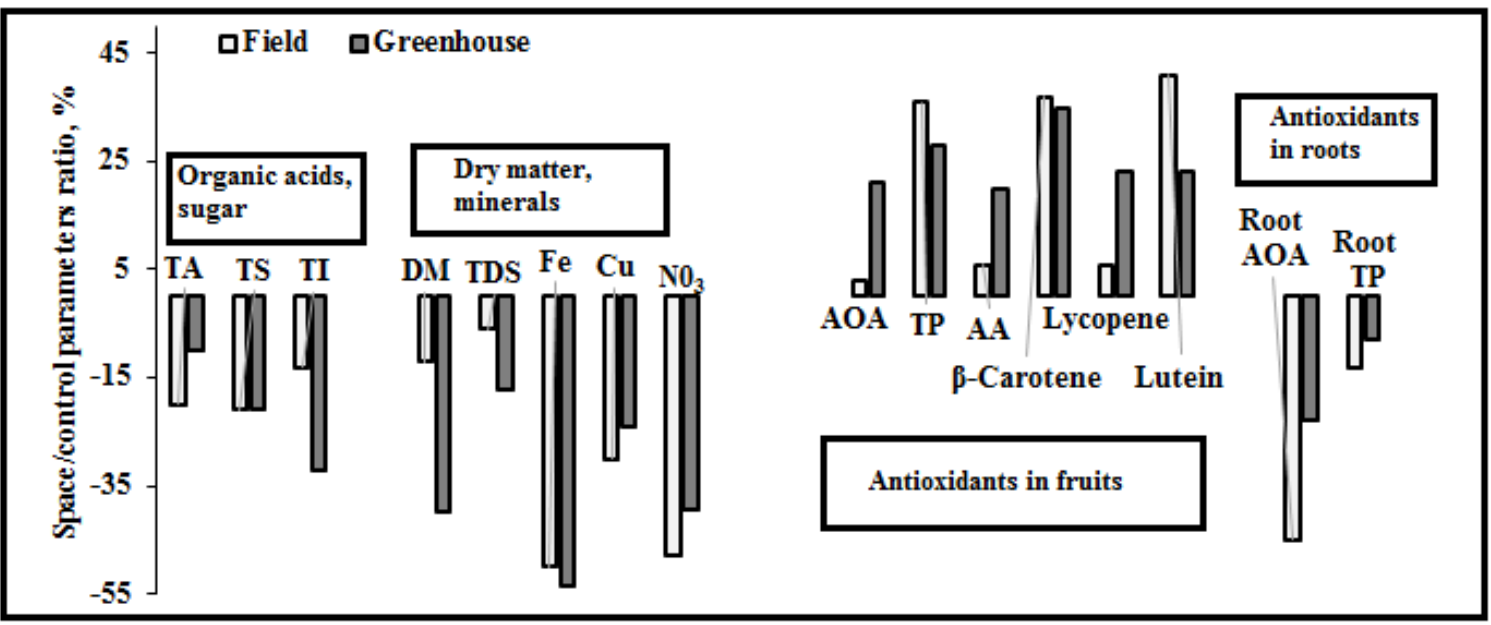

Figure 4. Differences in biochemical parameters and mineral content between control plants and plants derived from spaceflight-treated seeds grown in open field and in greenhouse.

On the other hand, the calculation of dry fruit weight indicated extremely small differences, or a lack of difference, between control plants and plants derived from spacestored seeds. In this respect, the fruit weight of control plants and plants grown from space-kept seeds reached $6.67 \pm 0.7 \mathrm{~g}$ and $5.17 \pm 0.5 \mathrm{~g} \mathrm{d.w.}$, respectively, in greenhouse and $3.69 \pm 0.3 \mathrm{~g}$ and $3.56 \pm 0.3 \mathrm{~g}$ d.w., respectively, in open field. The latter results indicate the increased dilution in fruits derived from space-stored seeds, as a long-term consequence of the effect of spaceflight on seed quality.

\section{Conclusions and Future Challenges}

Detailed biochemical and mineral characteristics of tomato fruits grown from spacekept seeds revealed the existence of significant oxidative stress in the plants, which was reflected in metabolic antioxidant content changes, a decrease in fruit quality and an increase in fruit yield. The phenomenon relevant to the recorded lowering of biological indicator values resulting from the space-kept seed utilization is dramatically important, though further studies are necessary to evaluate the associated mechanisms and modifications, particularly regarding antioxidant enzyme activity and carbohydrate profile in fruits.

Author Contributions: Conceptualization, E.D., G.N. and G.C.; data curation, T.Z.; formal analysis, T.Z. and G.N.; investigation, N.G., M.A., A.K. and I.K.; methodology, N.G., G.C. and E.D.; supervision, A.S. and G.C.; validation, G.C.; draft manuscript writing, N.G., M.A. and E.D.; manuscript revision and final editing, E.D., N.G. and G.C. All authors have read and agreed to the published version of the manuscript.

Funding: This research did not receive any grants from public, commercial or not-for-profit agencies.

Institutional Review Board Statement: Ethical review and approval were waived for this study, due to the involvement in the authorship of the Istitutions providing the seeds and managing the present research which did not require unusual materials of methods.

Informed Consent Statement: Informed consent was obtained from all subjects involved in the study.

Data Availability Statement: Not applicable.

Conflicts of Interest: The authors declare no conflict of interest. 


\section{References}

1. Visscher, A.M.; Seal, C.E.; Newton, R.J.; Frances, A.L.; Pritchard, H.W. Dry seeds and environmental extremes: Consequences for seed lifespan and germination. Funct. Plant Biol. 2016, 43, 656-668. [CrossRef] [PubMed]

2. Vandenbrink, J.P.; Kiss, J.Z. Space, the final frontier: A critical review of recent experiments performed in microgravity. Plant Sci. 2016, 243, 115-119. [CrossRef] [PubMed]

3. Paul, A.L.; Wheeler, R.M.; Levine, H.G.; Ferl, R.J. Fundamental plant biology enabled by the space shuttle. Am. J. Bot. 2013, 100, 226-234. [CrossRef] [PubMed]

4. Kordyum, E.; Chapman, D.; Brykova, V. Plant cell development and aging may accelerate in microgravity. Acta Astronaut. 2019, 157, 157-161. [CrossRef]

5. Musgrave, M.E. Seeds in space. Seed Sci. Res. 2007, 12, 1-17. [CrossRef]

6. Cannon, K.M.; Britt, D.T. Feeding one million people on Mars. New Space 2019, 7, 245-254. [CrossRef]

7. Wheeler, R.M. Agriculture for space: People and places paving the way. Open Agric. 2017, 2, 14-32. [CrossRef]

8. Paul, A.L.; Sng, N.J.; Zupanska, A.K.; Krishnamurthy, A.; Schultz, E.R.; Ferl, R.J. Genetic dissection of the Arabidopsis spaceflight transcriptome: Are some responses dispensable for the physiological adaptation of plants to spaceflight? PLoS ONE 2017, 12, e0180186. [CrossRef] [PubMed]

9. Poulet, L.; Fontaine, J.-P.; Dussap, C.-G. Plant's response to space environment: A comprehensive review including mechanistic modelling for future space gardeners. Bot. Lett. 2016, 163, 337-347. [CrossRef]

10. Lu, J.; Xue, H.; Pan, Y.; Kan, S.; Liu, M.; Nechitailo, G.S. Effect of spaceflight duration of subcellular morphologies and defense enzyme activities in earth-grown tomato seedlings propagated from space-flown seeds. Russ. J. Phys. Chem. B 2009, 3, 981-986. [CrossRef]

11. Jiyuan, L.; Zhenye, Q.; Yongcheng, S.; Tianjun, Q.; Jun, H. Seed growth experiments after space flight: The Chinese experience. In Selected Papers on Remote Sensing, Space Science and Information Technology; Seminars of the United Nations Programmer on Space Applications; United Nations: New York, NY, USA, 1999; Volume 10, p. 71.

12. Chandler, J.O.; Haas, F.B.; Khan, S.; Bowden, L.; Ignatz, M.; Enfissi, E.M.A.; Gawthrop, F.; Griffiths, A.; Fraser, P.D.; Rensing, S.A.; et al. Rocket Science: The effect of spaceflight on germination physiology, ageing, and transcriptome of Eruca sativa seeds. Life 2020, 10, 49. [CrossRef]

13. Nechitailo, G.; Jinying, L.; Huai, X.; Yi, P.R.; Chongqin, T.; Liu, M. Influence of long term exposure to space flight on tomato seeds. Adv. Space Res. 2005, 36, 1329-1333. [CrossRef]

14. Mishchenko, L.T.; Dunich, A.A.; Danilova, O.I. Impact of a real microgravity on the productivity of tomato plants and resistance to viruses. In Proceedings of the Life in Space for Life on Earth, Aberdeen, UK, 18-22 June 2012. ESA SP-706.

15. Kahn, B.A.; Stoffella, P.J. No evidence of adverse effects on germination, emergence, and fruit yield due to space exposure of tomato seeds. J. Am. Soc. Hortic. Sci. 1996, 121, 414-418. [CrossRef] [PubMed]

16. Ren, W.B.; Zhang, Y.; Deng, B.; Guo, H.; Cheng, L.; Liu, Y. Effect of space flight factors on alfalfa seeds. Afr. J. Biotechnol. 2010, 9, 7273-7279. [CrossRef]

17. De Micco, V.; Arena, C.; Pignalosa, D.; Durante, M. Effects of Sparsely and Densely Ionizing Radiation on Plants. Radiat. Environ. Biophys. 2011, 50, 1-19. [CrossRef]

18. Arena, C.; De Micco, V.; De Maio, A. Growth alteration and leaf biochemical responses in Phaseolus Vulgaris exposed to different doses of ionizing radiation. Plant Biol. 2014, 16, 194-202. [CrossRef]

19. Arena, C.; De Micco, V.; Aronne, G.; Pugliese, M.G.; Virzo, A.; DeMaio, A. Response of Phaseolus vulgaris L. plants to low-LET ionizing radiation: Growth and oxidative stress. Acta Astronaut. 2014, 91, 107-114. [CrossRef]

20. Zaka, R.; Vandecasteele, C.M.; Misset, M.T. Effects of low chronic doses of ionizing radiation on antioxidant enzymes and G6PDH activities in Stipa capillata (Poaceae). J. Exp. Bot. 2002, 53, 1979-1987. [CrossRef]

21. Arena, C.; De Micco, V.; Macaevac, E.; Quintens, R. Space radiation effects on plant and mammalian cells. Acta Astronaut. 2014, 104, 419-431. [CrossRef]

22. Fleming, M.B.; Patterson, E.L.; Reeves, P.A.; Richards, C.M.; Gaines, T.A.; Walters, C. Exploring the fate of mRNA in aging seeds: Protection, destruction, or slow decay? J. Exp. Bot. 2018, 69, 4309-4321. [CrossRef] [PubMed]

23. Fleming, M.B.; Hill, L.M.; Walters, C. The kinetics of ageing in dry-stored seeds: A comparison of viability loss and RNA degradation in unique legacy seed collections. Ann. Bot. 2019, 123, 1133-1146. [CrossRef] [PubMed]

24. Alpatiev, A.V.; Skvortsova, R.V.; Gurkina, L.K. Guidelines for the selection of tomato for phytophtorosis resistance. In Greenhouse and Field Conditions; VNIISSOK: Moscow, Russia, 1986; pp. 36-45. (In Russian)

25. AOAC Association Official Analytical Chemists. The Official Methods of Analysis of AOAC International; 22 Vitamin C; AOAC: Rockville, MD, USA, 2012.

26. Golubkina, N.A.; Kekina, H.G.; Molchanova, A.V.; Antoshkina, M.S.; Nadezhkin, S.M.; Soldatenko, A.V. Plants Antioxidants and Methods of Their Determination; Infra-M: Moscow, Russia, 2020. [CrossRef]

27. Swamy, P.M. Laboratory Manual on Biotechnology; Rastogi: New Delhi, India, 2008; p. 617.

28. Navez, B.; Letard, M.; Graselly, D.; Jost, J. Les critéres de qualité de la tomate. Infos-Ctifl 1999, 155, 41-47.

29. Sumalan, R.M.; Ciulca, S.I.; Poiana, M.A.; Moigradean, D.; Radulov, I.; Negrea, M.; Crisan, M.E.; Copolovici, L.; Sumalan, R.L. The Antioxidant profile evaluation of some tomato landraces with soil salinity tolerance correlated with high nutraceutical and functional value. Agronomy 2020, 10, 500. [CrossRef] 
30. Riccioni, G. Carotenoids and cardiovascular disease. Curr. Atheroscler. Rep. 2009, 11, 434-439. [CrossRef] [PubMed]

31. Keikel, M.; Schumacher, M.; Dicato, M.; Diederich, M. Antioxidant and anti- proliferative properties of lycopene. Free Radic. Res. 2011, 45, 925-940. [CrossRef]

32. Du, J.; Cullen, J.J.; Buettner, G.R. Ascorbic acid: Chemistry, biology and the treatment of cancer. Biochim. Biophys. Acta 2012, 1826, 443-457. [CrossRef]

33. Del Río, D.; Rodríguez-Mateos, A.; Spencer, J.P.E.; Tognolini, M.; Borges, G.; Crozier, A. Dietary (poly)phenolics in human health: Structures, bioavailability, and evidence of protective effects against chronic diseases. Antioxid. Redox Signal. 2013, 18, 1818-1892. [CrossRef]

34. Siddiqui, M.W.; Ayala-Zavala, J.F.; Dhua, R.S. Genotypic variation in tomatoes affecting processing and antioxidant properties. Crit. Rev. Food Sci. Nutr. 2015, 55, 1819-1835. [CrossRef]

35. Akram, N.A.; Shafiq, F.; Ashraf, M. Ascorbic Acid-A Potential Oxidant Scavenger and Its Role in Plant Development and Abiotic Stress Tolerance. Front. Plant Sci. 2017, 8, 613. [CrossRef]

36. Toor, R.K.; Savage, G.P. Antioxidant activities in different fractions of tomatoes. Food Res. Int. 2005, 38, 487-494. [CrossRef]

37. Batista-Silva, W.; Naschimento, V.L.; Medeiros, D.B.; Nunes-Besi, A.; Ribeiro, D.M.; Zsoson, A.; Araujo, W.L. Modification of organic acids profile during fruit development and ripening: Correlation of causation? Front. Plant Sci. 2018, 9, 1689. [CrossRef] [PubMed]

38. Aoun, A.B.; Lechiheb, B.; Benyahya, L.; Ferchichi, A. Evaluation of fruit quality traits of traditional varieties of tomato (Solanum lycopersicum) grown in Tunisia. Afr. J. Food Sci. 2013, 7, 350-354. [CrossRef]

39. Davies, J.N.; Hobson, G.E. The constituents of tomato fruit-The influence of environment, nutrition, and genotype. Crit. Rev. Food Sci. Technol. 1981, 15, 205-280. [CrossRef]

40. Etienne, A.; Génard, M.; Lobit, P.; Mbeguié-A-Mbéguié, D.; Bugaud, C. What controls fleshy fruit acidity? A review of malate and citrate accumulation in fruit cells. J. Exp. Bot. 2013, 64, 1451-1469. [CrossRef] [PubMed]

41. Figàs, M.R.; Prohens, J.; Raigón, M.D.; Fita, A.; García-Martínez, M.D.; Casanova, C.; Borràs, D.; Plazas, M.; Andújar, I.; Soler, S. Characterization of composition traits related to organoleptic and functional quality for the differentiation, selection and enhancement of local varieties of tomato from different cultivar groups. Food Chem. 2015, 187, 517-524. [CrossRef]

42. Causse, M.; Friguet, C.; Coiret, C.; Lépicier, M.; Navez, B.; Lee, M.; Holthuysen, L.; Sinesio, F.; Moneta, E.; Grandillo, S. Consumer preferences for fresh tomato at the European scale: A common segmentation on taste and firmness. J. Food Sci. 2010, 75, S531-S541. [CrossRef] [PubMed]

43. Beckles, D.M. Factors affecting the postharvest soluble solids and sugar content of tomato (Solanum lycopersicum L.) fruit. Postharvest Biol. Technol. 2012, 63, 129-140. [CrossRef]

44. Fernández-Ruiz, V.; Sánchez-Mata, M.C.; Cámara, M.; Torija, M.E.; Chaya, C.; Galiana-Balaguer, L.; Roselló, S.; Nuez, F. Internal quality characterization of fresh tomato fruits. HortScience 2004, 39, 339-345. [CrossRef]

45. Keunen, E.; Peshev, D.; Vangronsveld, J.; ENDE, W.V.D.; Cuylers, A. Plant sugars are crucial players in the oxidative challenge during abiotic stress: Extending the traditional concept. Plant Cell Environ. 2013, 36, 1242-1255. [CrossRef]

46. Rout, G.R.; Sahoo, S. Role of iron in plants growth and metabolism. Rev. Agric. Sci. 2015, 3, 1-24. [CrossRef]

47. Sakya, A.; Sulandjari, T. Foliar iron application on growth and yield of tomato. IOP Conf. Ser. Earth Environ. Sci. 2019, 250, 012001. [CrossRef]

48. Yruela, I. Copper in plants. Braz. J. Plant Physiol. 2005, 17, 145-156. [CrossRef] 